\title{
A CRIMINALIZAÇÃO BIOPOLÍTICA DA POBREZA A PARTIR DO CONTO "O OUTRO”, DE RUBEM FONSECA
}

\author{
THE BIOPOLITICAL CRIMINALIZATION OF POVERTY FROM THE TALE “O OUTRO”, BY \\ RUBEM FONSECA
}

\author{
Maiquel Angelo Dezordi Wermuth \\ Doutor em Direito Público (UNISINOS) \\ UNIJUÍ - Universidade Regional do Noroeste do Estado do Rio Grande do Sul \\ Rio Grande do Sul/RS. Brasil \\ madwermuth@gmail.com \\ André Giovane de Castro \\ Doutorando em Direitos Humanos (UNIJUÍ) \\ UNIJUÍ - Universidade Regional do Noroeste do Estado do Rio Grande do Sul \\ Rio Grande do Sul/RS. Brasil \\ andre_castro500@hotmail.com
}

Resumo: A desigualdade social constitui-se como fator embrionário significativo da violência. A partir da disparidade socioeconômica e criminalização da pobreza, o artigo científico problematiza a construção e/ou seleção dos grupos considerados perigosos ao convívio em coletividade. O objetivo funda-se em analisar o estereótipo do "estranho", "inimigo" e "criminoso" na figura dos sujeitos pertencentes às classes subalternizadas à luz do conto "O outro", de Rubem Fonseca, desvelando os contornos biopolíticos. Com orientação do método fenomenológico-hermenêutico, abordagem qualitativa, técnica exploratória e procedimentos bibliográfico e documental, a pesquisa vislumbra a desigualdade social como elemento de configuração do pobre como "estranho", "inimigo" e "criminoso" a ser constituído em vida nua e eliminado do tecido societal, no bojo de uma verdadeira "Criminologia do Outro".

Palavras-chave: Desigualdade social. Seletividade. Violência.

Abstract: Social inequality is a significant embryonic factor in violence. From the socioeconomic disparity and criminalization of poverty, the scientific article problematizes the construction and/or selection of groups considered dangerous to coexistence in collectivity. The objective is based on analyzing the stereotype of the "stranger", "enemy" and "criminal" in the figure of subjects belonging to the subalternized classes in the light of Rubem Fonseca's tale "O outro", revealing the biopolitical contours. With the orientation of the phenomenologicalhermeneutic method, qualitative approach, exploratory technique and bibliographic and documentary procedures, the research glimpses social inequality as element of configuration of the poor as "strange", "enemy" and "criminal" to be constituted in naked life and eliminated from the societal fabric, in the bulge of a true "Criminology of the Other".

Keywords: Social inequality. Selectivity. Violence.

Para citar este artigo (ABNT NBR 6023:2018)

WERMUTH, Maiquel Angelo Dezordi; CASTRO, André Giovane de. A criminalização biopolítica da pobreza a partir do conto "O Outro", de Rubem Fonseca. Revista Thesis Juris RTJ, São Paulo, v. 9, n. 2, p. 281-300, jul./dez. 2020. http://doi.org/10.5585/rtj.v9i2.16946. 
WERMUTH, Maiquel Angelo Dezordi; CASTRO, André Giovane de. A criminalização biopolítica da pobreza a partir do conto "O Outro", de Rubem Fonseca

\section{Introdução}

Um dos temas de maior discussão na atualidade refere-se à desigualdade social. A disparidade socioeconômica desencadeia um complexo de problemas para o Estado e para a sociedade. Esse é o caso da violência. A criminalidade mostra-se inserida nas diversas classes sociais, mas o aparato repressivo-punitivo delineado contemporaneamente aparenta eleger e culpabilizar uma determinada categoria pelos medos, pelas ameaças e pelos perigos da sociedade. Os causadores da insegurança são corporificados, assim, com características afeitas a uma parcela populacional colocada e mantida, historicamente, à margem.

A condição socioeconômica torna-se, com efeito, elementar para a compreensão dos sujeitos estigmatizados como "estranhos", "inimigos" e, via de consequência, "criminosos" no âmbito da violência combatida institucional e socialmente. A presente investigação científica, com supedâneo na matriz teórica da biopolítica, assenta-se na seguinte problemática: em que medida a pobreza implica a categorização de indivíduos como responsáveis pela violência socialmente difusa e, consequentemente, estigmatiza os membros das classes subalternizadas como "estranhos", "inimigos" e "criminosos"?

O estudo, a partir do problema aventado, surge da hipótese de que a sociedade contemporânea define os sujeitos considerados como "estranhos", “inimigos" e, logo, como responsáveis pelos medos, pelas ameaças e pelos perigos. O fator socioeconômico, especialmente porque os pobres demandam a atenção assistencial do Estado e porque são vistos como inúteis ao sistema econômico, parece ser um elemento nevrálgico à configuração dos "criminosos", o que evidencia a mitigação da condição humana e a materialização do que se denomina de "Criminologia do Outro".

A importância de se compreender o papel do cidadão, no âmago de sociedade marcada por significativas diferenças, à observância dos direitos humanos e à valorização do "outro" como a imagem do "eu" justifica o desenvolvimento desta pesquisa. O marco teórico da biopolítica, com base no "método" fenomenológico-hermenêutico, na abordagem qualitativa, na técnica exploratória e nos procedimentos bibliográfico e documental, viabiliza, à luz do conto literário "O outro", de Rubem Fonseca, a realização de um percurso teórico-crítico em torno da desigualdade social e da violência.

A fenomenologia hermenêutica, adotada com alicerce nas lições de Martin Heidegger (1998) e Hans-Georg Gadamer (1999), mostra-se oportuna em virtude de autorizar o alcance dos intentos deste trabalho acadêmico. Não se busca tão só descrever a realidade, mas, sim, desvelar as nuanças envolventes do cenário, essencialmente no Brasil, no tocante à construção 
WERMUTH, Maiquel Angelo Dezordi; CASTRO, André Giovane de. A criminalização biopolítica da pobreza a partir do conto "O Outro", de Rubem Fonseca

do "estranho", "inimigo" e "criminoso". Este "método" constitui-se como instrumento hábil ao desabrochar dos meandros do poder, no bojo do qual os sujeitos-pesquisadores sentem os seus efeitos.

A fenomenologia, definida como estudo do fenômeno, vincula-se com a hermenêutica, definida como ferramenta de vislumbre do assunto. Assim, o sobredito "método" oportuniza, a teor de Ernildo Stein (2001, p. 169), o acesso "ao fenômeno no sentido fenomenológico", de modo a descortinar o que "primeiramente e o mais das vezes não se dá como manifesto". Essa é, aliás, a missão dos sujeitos-pesquisadores. Por isso, com o horizonte visto com os olhos da historicidade e da tradição, à luz das teorias filosóficas heideggeriana (1998) e gadameriana (1999), a fenomenologia hermenêutica viabiliza o desvelamento das coisas em si mesmas.

O artigo, por fim, estrutura-se em três seções e objetiva, respectivamente, a discutir as seguintes provocações: a) analisar a pobreza como fator de configuração institucional e social do "estranho", "inimigo" e "criminoso"; b) refletir, com base no conto "O outro", de Rubem Fonseca, a relação dicotômica entre sujeitos de classes economicamente antagônicas; e c) identificar, com supedâneo nas perspectivas da biopolítica, a retratação contemporânea dos indivíduos selecionados como "estranhos", "inimigos" e "criminosos" com referência à figura do homo sacer e, portanto, da vida nua.

\section{A pobreza e a configuração do "estranho", "inimigo" e "criminoso"}

A desigualdade social, nos seus mais diversos aspectos, não é novidade do tempo atual. A disparidade econômica constitui-se como um fator incutido no tecido societal há milênios e conforma as relações entre o Estado e os indivíduos. O ente estatal, com o ideal de maximização dos interesses coletivos, tem a funcionalidade de atuar em prol de todos e, especialmente, das camadas menos favorecidas ${ }^{1}$. Tal intento, contudo, nem sempre se torna concreto ou, quando há a atuação do poder público, os efeitos nem sempre são benéficos àqueles que se encontram em situação de hipossuficiência econômica.

O sistema econômico, notadamente estruturado na atualidade sob um viés capitalista, modificou-se nas últimas décadas do século XX, essencialmente motivado pelo fenômeno da globalização alavancado com o fim da Segunda Guerra Mundial. A organização das pautas de governo, ao mesmo tempo, sofreu alteração, o que é perceptível no âmbito das conexões

\footnotetext{
${ }^{1}$ No Brasil, a função estatal de atuar em prol das classes economicamente hipossuficientes situa-se legalmente prevista na Constituição Federal de 1988, que instituiu um Estado Democrático de Direito, ao estabelecer, em seu artigo $3^{\circ}$, como objetivos fundamentais da República Federativa do Brasil a construção de uma sociedade livre, justa e solidária; a garantia do desenvolvimento nacional; a erradicação da pobreza e da marginalização e redução das desigualdades sociais e regionais; e a promoção do bem de todos, sem preconceitos de origem, raça, sexo, cor, idade e quaisquer outras formas de discriminação (BRASIL, 1988).
} 
WERMUTH, Maiquel Angelo Dezordi; CASTRO, André Giovane de. A criminalização biopolítica da pobreza a partir do conto "O Outro", de Rubem Fonseca

possíveis entre a economia e a violência ${ }^{2}$, uma vez que a atuação assistencial e caritativa do Estado de bem-estar social foi deixada de lado para abrir espaço à ação repressivo-punitiva do Estado penal ou policialesco ${ }^{3}$.

A substituição de um modelo de Estado destinado a atender, preponderantemente, as demandas das classes menos abastadas por um modelo de Estado direcionado a agir, sobremaneira, frente àqueles considerados como os párias da ordem social cria um paradoxo sobre os interesses da sociedade - principalmente, no que se refere à burguesia. Isso é nítido na reflexão de Miguel Tedesco Wedy (2016) acerca das relações neoliberais, uma vez que, de um lado, se almeja um Estado menos interventivo no setor econômico, ao passo que, de outro lado, se pleiteia um Estado mais presente na esfera criminal.

Com efeito, no entendimento de João Ricardo Dornelles (2008, p. 30), o Estado centrase em um "aparato repressivo em relação às condutas desviadas e transgressoras da lei e do controle dos grupos considerados ameaçadores da nova ordem, principalmente com a exclusão social de enormes contingentes humanos", embora haja, ainda, a necessidade de ações focadas nos anseios dos conglomerados sociais. De todo modo, o que se constata é uma redefinição dos mecanismos utilizados pelo ente estatal, pois a população destinatária do Estado providência e do Estado penitência é a mesma: os pobres.

Diante disso, o Estado não deixa de agir sobre as camadas economicamente hipossuficientes. O que ocorre é tão somente uma mutação na forma de atuação e no objetivo a ser alcançado. Se o enfoque assistencial do Estado caritativo tem o intuito de criar condições para a vida digna das pessoas situadas à margem da sociedade, o pressuposto repressivopunitivo do Estado penal tem o interesse de retirar do convívio social aqueles grupos considerados, especialmente dada a situação socioeconômica, como "estranhos", "inimigos" e, logo, “criminosos", isto é, responsáveis pela violência a ser combatida.

A situação brasileira circunscreve-se em um cenário assim estruturado. O Brasil é retratado por Dornelles (2008) pela exclusão, pela concentração de riqueza e pela injustiça, cujo contexto resulta em um sistema de justiça criminal destinado a abarcar os segmentos sociais mais vulneráveis, como é o caso dos pobres, em que pese não sejam os únicos alvos do controle

\footnotetext{
${ }^{2}$ A violência é concebida por Hannah Arendt (1985) como um fator sempre marcante nas atividades humanas, em que pese tenham sido raros os momentos em que fosse objeto de atenção. A tese arendtiana (1985) é de que a diminuta consideração dada à violência se deve em razão de sua normalização na sociedade, justamente porque aquilo considerado corriqueiro e, logo, óbvio deixaria de ser questionado e examinado. ${ }^{3} \mathrm{O}$ avanço de políticas criminais mais austeras, marcadas pela forte atuação do Estado sobre grupos determinados, pelo encarceramento em massa de um perfil tradicionalmente marginalizado e pela infringência de direitos humanos, pode ser relacionado, na contemporaneidade, àquilo que Ulrich Beck (2010) denomina de sociedade de risco. A sociedade de risco é fruto dos medos, das incertezas, das inseguranças causados pelo denso processo de globalização, cuja constante criação e mutação, essencialmente vinculadas às áreas de ciência e tecnologia, faz com que nada seja permanente e duradouro, nem mesmo as relações interpessoais, que, na interpretação de Zygmunt Bauman (2014), são líquidas. Logo, a sensação de medo é cultivada no seio social frente aos novos riscos, com o que surge a necessidade de se criar mecanismos de enfrentamento aos "identificados" sujeitos supostamente causadores das ameaças e dos perigos. Nesse sentido, emerge o recrudescimento do aparato jurídico-criminal.
} 
social. Porém, o discurso de medo, perigo e insegurança fortalece, na visão de Dornelles (2008, p. 38), um consenso junto ao tecido societal para a adoção de "políticas repressivas e opressoras contra as classes populares e segmentos não-privilegiados".

Aliás, os seres humanos tendem a necessitar de escoadouros para se sentirem seguros e confiantes. Uma sociedade marcadamente transformadora - o que é próprio da globalização na contemporaneidade - parece, no entanto, dificultar a criação de mecanismos perenes para oportunizar a segurança e a confiança. Por isso, na concepção de Zygmunt Bauman (2009, p. 15), no instante em que se compreende a impossibilidade de se alcançar a ordem, “[...] só conseguimos explicar o fracasso imaginando que ele se deve a um ato mau e premeditado, o que implica a existência de algum delinquente".

Em uma conjuntura assim delineada, surge a necessidade de se criar o estereótipo do "estranho", "inimigo" e "criminoso" a ser combatido. Trata-se de corporificar os medos, as inseguranças e os perigos em um contingente populacional definido, motivo pelo qual, segundo Bauman (2007, p. 90-91),

\section{na maioria das ocasiões, as ansiedades acumuladas tendem a ser descarregadas sobre uma categoria selecionada de "estranhos", escolhidos para resumir a "estranheza": a pouca familiaridade e a obscuridade do ambiente de vida, a incerteza dos riscos e a natureza desconhecida das ameaças. Ao se expulsar uma categoria selecionada de "estranhos" de seus lares e lojas, o fantasma ameaçador da insegurança é, por algum tempo, exorcizado; o aterrorizante monstro da insegurança é aparentemente expulso.}

O dilema reside no fato de que a classe constituída na figura de ameaça tende a não se extinguir. A sociedade, por isso, mantém constantemente a tarefa de definir os indivíduos integrantes do grupo considerado responsável pelos riscos sociais. Tais sujeitos, conforme Bauman (2007), são vistos com intenções que, no máximo, se podem supor, embora em momento algum se tenha a convicção de que, de fato, sejam capazes de externar o complexo de perigos que os circundam, de modo que a simples presença no mesmo espaço geográfico seja suficiente para desconcertar o convívio entre os iguais.

O caso dos membros das camadas economicamente hipossuficientes é nítido no que se refere à configuração do "estranho", "inimigo" e "criminoso" na sociedade contemporânea, principalmente se considerada sob a ótica da alternância do Estado de bem-estar social para o Estado penal. A realidade dos Estados Unidos, mas cujo contexto se faz semelhante em outros países, a exemplo do Brasil, demonstra, de acordo com Loïc Wacquant (2007, p. 96, grifos do autor), a atuação estatal alicerçada na substituição abrupta de uma "guerra contra a pobreza" para uma "guerra contra os pobres". 
A guinada desencadeada pelo Estado desde o fim do século XX centra-se, diante disso, em não retirar os pobres da atenção estatal, mas, sim, em mudar a área do seu foco. Nesse sentido, os integrantes da sociedade com baixas condições econômicas e, via de consequência, neutros ou mesmo inúteis à ordem do capital são vistos como incômodos ao crescimento econômico dada a necessidade de políticas públicas que os auxiliem monetariamente a uma vida mais digna. Os pobres, assim, consoante Bauman (1998, p. 59), "longe de fazer jus a cuidado e assistência, merecem ódio e condenação [...]".

Os tempos contemporâneos, especialmente em virtude da globalização, externam-se pela transitoriedade. É como se fazer parte do corpo social fosse o resultado da adequação aos novos e contínuos critérios estabelecidos por parcela da sociedade - notadamente, por aqueles que detêm o capital. Os seres humanos são retirados de sua condição de pessoa e unicamente representados, na acepção de Bauman (1999, p. 94, grifos do autor), como consumidores, esquecendo-se do fato de que "[todo] mundo pode ser lançado na moda do consumo; todo mundo pode desejar ser um consumidor e aproveitar as oportunidades que esse modo de vida oferece", embora "nem todo mundo pode ser consumidor".

Não pertencer ou não se adequar ao seleto grupo dos iguais - leia-se: consumidores, burgueses, detentores dos meios de produção - faz do "outro" um "estranho", "inimigo" e “criminoso", razão pela qual, na análise de Bauman (1998, p. 59, grifos do autor), “[cada] vez mais, ser pobre é encarado como um crime". Mais do que isso, o confinamento geográfico fruto da segregação social - corrobora a configuração do sujeito perigoso, justamente porque os “[...] tipos mais comuns de criminosos na visão do público vêm quase sem exceção da 'base' da sociedade" (BAUMAN, 1999, p. 134).

A partir disso, o "outro", em que pese detenha a mesma gênese humana, é concebido como um "estranho" e, segundo Bauman (1999, p. 115-116), “[...] lançado numa condição de forçada estranheza, guardada e cultivada pelas fronteiras espaciais estritamente vigiadas, mantido a distância e impedido de ter um acesso comunicativo regular ou esporádico [...]”. Trata-se, a bem da verdade, de considerar o diferente como indesejável, como ameaçador, como perigoso, motivo pelo qual o afastamento do espaço privilegiado dos “iguais" é indispensável para se restabelecer a harmonia.

Um contexto assim delineado valida o aparelho repressivo-punitivo do Estado. O "estranho", "inimigo" e "criminoso" ensejam a atuação estatal porque representam os medos, as ameaças e as inseguranças da vida social. Nesse sentido, conforme Aline Ferreira da Silva Diel e Maiquel Ângelo Dezordi Wermuth (2018, p. 127-128), a conformação da imagem do “inimigo" oportuniza que "se acalore e se emancipe a banalização da retórica punitiva, até que 
WERMUTH, Maiquel Angelo Dezordi; CASTRO, André Giovane de. A criminalização biopolítica da pobreza a partir do conto "O Outro", de Rubem Fonseca

esta se extenue em um mero método estatal de organização, e deixe de atormentar, até mesmo, os corações mais sensíveis frente às rupturas sistemáticas com a dignidade humana".

A sociedade vive a dificuldade de conviver com a diferença e a incapacidade de suportar a multiplicidade de seres humanos, essencialmente porque, consoante Bauman (2014, p. 135), "quanto mais eficazes a tendência à homogeneidade e o esforço para eliminar a diferença, tanto mais difícil sentir-se à vontade em presença de estranhos, tanto mais ameaçadora a diferença e tanto mais intensa a ansiedade que ela gera”. Logo, a diferença, ao mesmo tempo em que cria laços de pertença entre os iguais, segrega o "outro" visto como "estranho", "inimigo" e "criminoso", como é o caso dos membros das classes marginalizadas.

A marginalização afeta, sobretudo, os integrantes das camadas economicamente mais vulneráveis. O aparato jurídico-criminal é direcionado aos pobres, os quais, a teor de Érick de Freitas Mendes e Rafael Lazzarotto Simioni (2020, p. 62), têm reforçada a "exteriorização do estranhamento do outro". Esse não é o resultado somente da execução da lei, senão, isto sim, também, da sua criação, pois a criminalização seletiva realizada em face das "camadas sociais paupérrimas ocorre desde o processo legislativo de elaboração de normas e se estende até aos agentes e instituições que detêm poder de polícia” (MENDES; SIMIONI, 2020, p. 63).

Os números sobre o sistema carcerário brasileiro evidenciam a seletividade criminal. O Levantamento Nacional de Informações Penitenciárias - Atualização - Junho de 2017 indica 726.354 indivíduos sob a custódia do Estado. Desta cifra, 95\% são homens ${ }^{4} ; 63,64 \%$ são pardos ou pretos $^{5} ; 54,06 \%$ são jovens ${ }^{6}$; e $60,65 \%$ não possuem sequer o ensino fundamental completo ${ }^{7}$. A respeito dos tipos penais imputados aos presos, a predominância refere-se aos delitos relacionados ao patrimônio e ao tráfico de drogas ${ }^{8}$. Identifica-se, nesse sentido, um perfil específico de segregados no país.

\footnotetext{
${ }^{4} \mathrm{O}$ número de mulheres presas, com data-limite das estatísticas de 2016, é de 42,4 mil. O acréscimo do encarceramento feminino deu-se da seguinte forma: em 2000, havia 5,6 mil; em 2001, 5,7 mil; em 2002, 5,9 mil; em 2003, 9,9 mil; em 2004, 16,5 mil; em 2005, 12,9 mil; em 2006, 17,2 mil; em 2007, 19,0 mil; em 2008, 21,6 mil; em 2009, 24,3 mil; em 2010, 28,2 mil; em 2011, 29,3 mil; em 2012, 31,6 mil; em 2013, 32,9 mil; em 2014, 33,8 mil; e, em 2015, 37,4 mil (BRASIL, 2018).

${ }^{5}$ A população brasileira conta com $46,8 \%$ de pardos, $43,6 \%$ de brancos e $8,6 \%$ de pretos, cujas cores/etnias - importa salientar - resultam de autodeclaração dos cidadãos. Já a população prisional comporta 46,27\% de pardos, $35,48 \%$ de brancos, $17,37 \%$ de negros, $0,67 \%$ de amarelos e $0,22 \%$ de indígenas (BRASIL, 2019).

${ }^{6}$ Em relação à faixa etária, 29,95\% possuem de 18 a 24 anos; $24,11 \%$, de 25 a 29 anos; $18,33 \%$, de 30 a 34 anos; $19,45 \%$, de 35 a 45 anos; $6,92 \%$, de 46 a 60 anos; $1,04 \%$, de 61 a 70 anos; e $0,2 \%$, mais de 70 anos (BRASIL, 2019).

${ }^{7}$ No tocante à escolaridade, o contingente segregado divide-se em 3,45\% de analfabetos; 5,85\% de alfabetizados; $51,35 \%$ com ensino fundamental incompleto; $13,15 \%$ com ensino fundamental completo; $14,98 \%$ com ensino médio incompleto; $9,65 \%$ com ensino médio completo; $0,95 \%$ com ensino superior incompleto; $0,56 \%$ com ensino superior completo; e $0,04 \%$ com ensino acima de superior completo (BRASIL, 2019).

${ }^{8}$ Os crimes contra o patrimônio registram 234.866 incidências; os crimes de drogas, 156.749; os crimes contra a pessoa, 64.048; os crimes do Estatuto do Desarmamento, 24.122; os crimes contra a dignidade sexual, 20.906; os crimes contra a paz pública, 8.874; os crimes de legislações específicas, 4.919; os crimes contra a fé pública, 3.169; os crimes de trânsito, 1.435; os crimes praticados por particular contra a Administração Pública, 680; e os crimes contra a Administração Pública, 483 (BRASIL, 2019)
} 
Os marcadores de escolaridade e de incidência de delitos têm o condão de desvelar o recorte socioeconômico. Trata-se de uma constatação interseccional ${ }^{9}$. De um lado, porque, em que pese não seja um critério vinculativo, a instrução educacional tende a resultar, à medida do seu avanço, melhores condições de renda. De outro lado, porque, no que se refere à ocorrência de delitos a que os reclusos foram condenados ou estão sendo processados, há prevalência de tipos penais patrimoniais e atrelados a entorpecentes. Verifica-se, uma vez mais, a criminalização da pobreza.

O sistema de justiça penal, segundo Jacqueline Sinhoretto e Renato Sérgio de Lima (2015), preocupa-se, essencialmente, com a circulação, considerada necessária ou indevida, da riqueza e, logo, dirige-se contra os segmentos menos abastados para o enfrentamento dos crimes, por exemplo, de furtos, roubos e tráfico de drogas. São modalidades ilícitas, conforme Camila Caldeira Nunes Dias (2017), com a relação histórica das camadas subalternizadas, as quais, por conseguinte, se tornam os alvos preferenciais das instituições. Esse é, ainda, o cenário do Brasil contemporâneo.

O perfil dos custodiados certifica, na leitura de Sinhoretto e Lima (2015, p. 126), que "a vigilância policial - que prende em flagrante delito - está concentrada sobre ladrões de pequenas quantias e sobre traficantes de pequenas quantidades". Assim, consoante Débora Regina Pastana (2013, p. 44), incrementando as celas, "cada vez mais e por mais tempo", com as classes pobres, "desvia-se, de forma estratégica, a atenção dos inúmeros crimes contra a ordem econômica e financeira praticados pela elite política", o que se faz factível perante a irrisória incidência de infrações penais contra a Administração Pública no rol dos reclusos.

O encarceramento, especialmente no Brasil, tem uma caminhada de adversidades. Para Sara de Araújo Pessoa e Fernanda da Silva Lima (2019, p. 281), aliás, o "aprisionamento é inquestionavelmente uma história de injustiça" com o rosto, principalmente, dos indivíduos situados “à margem da sociedade". A seletividade penal, com efeito, constitui-se e manifestase baseada em uma lógica, a qual, inversamente das funções declaradas e formais, se erige em funções latentes e reais, cujo desiderato é, então, o triunfo da prisão como "instrumento de marginalização e ratificação de desigualdades e violência” (PESSOA; LIMA, 2019, p. 282).

A marginalização socioeconômica, portanto, além de provocar obstáculos à vida digna aos seres humanos que se encontram nessa condição, é concebida como elemento substancial à

\footnotetext{
${ }^{9} \mathrm{O}$ enlaçamento dos critérios valorativos com o intuito de identificar a condição fática dos indivíduos, o que, no caso em apreço, se refere ao atributo socioeconômico, notabiliza a interseccionalidade. Trata-se de uma ferramenta analítica interessante sobre variados olhares, os quais não são vislumbrados em sua singularidade, mas, sim, na conectividade de uns com os outros. É o caso da classe, do gênero e da raça, considerados como mecanismos institucionais ou sociais de discriminação, de opressão, de subjugação. Essa simbiose entre os fenômenos autoriza uma conclusão mais satisfatória. Por isso, a definição socioeconômica não se vincularia tão só, se fosse o caso, à renda, senão, isto sim, a outros elementos, concebidos, na cena em tela, como o grau de escolaridade e a incidência de delitos, cujos elementos conduzem ou corroboram a conjuntura de desigualdade.
} 
WERMUTH, Maiquel Angelo Dezordi; CASTRO, André Giovane de. A criminalização biopolítica da pobreza a partir do conto "O Outro", de Rubem Fonseca

configuração do "estranho", "inimigo" e "criminoso". O pobre, ao ser desassistido pelo Estado caritativo e abrigado pelo manto do Estado penal, é transformado em um ser cuja presença causa desconforto. Frente a tal cenário, analisa-se a seguir o conto "O outro", de Rubem Fonseca, como a retratação literária da diferença, notadamente socioeconômica, como fator de estranheza, de medo, de insegurança, de inquietude, de desconcerto.

\section{$2 \mathrm{O}$ desconcerto do "eu" versus o "outro" no conto de Rubem Fonseca}

O conto "O outro", de Rubem Fonseca (1975), integra o livro "Feliz ano novo" e permite uma importante análise sobre o relacionamento social entre dois indivíduos em situação antagônica. De um lado, um executivo excessivamente dedicado ao seu trabalho, mas insatisfeito com os resultados ao término do dia, e aparentemente detentor de um status econômico considerável, embora apresente sintomas de taquicardia. De outro lado, um menino rotineiramente vagando pelas ruas e solicitando dinheiro, o que demonstra se inserir no status inferior da pirâmide social.

A história retrata um conjunto de acontecimentos entre o executivo e o pedinte. A trama inicia com o detalhamento da rotina exaustiva do profissional e a menção a uma forte taquicardia sofrida por ele no mesmo dia em que o menino, pela primeira vez, lhe pedira dinheiro. No dia seguinte, por recomendação médica, o executivo decide caminhar e, no percurso, encontra, novamente, o jovem que, ao requerer e ser atendido com alguns "trocados", é identificado, então, como "um homem branco, forte, de cabelos castanhos compridos" (FONSECA, 1975, p. 70).

A cena repetiu-se no dia seguinte. O menino, ao ser questionado pelo executivo - "Mas todo dia?" (FONSECA, 1975, p. 70) -, alegou necessitar de dinheiro para adquirir remédio porque a sua mãe se encontrava à beira da morte, no que recebeu cem cruzeiros. Alguns dias depois, no entanto, o pedinte disse que sua mãe havia morrido e precisava custear o funeral, momento em que o executivo decidiu andar rapidamente para se desvencilhar dele, mas, após ouvir "morreu, morreu, morreu" (FONSECA, 1975, p. 70), preencheu um cheque no valor de cinco mil cruzeiros, ordenando: “Agora chega!” (FONSECA, 1975, p. 70).

O encontro, contudo, não seria o último. Poucos dias na sequência, o executivo visualizou o jovem e tentou caminhar em sentido contrário para não precisar, mais uma vez, entregar dinheiro, mas a tentativa foi em vão: 
[...] Apressei o passo, sentindo um aperto no coração, era como se eu estivesse sendo perseguido por alguém, um sentimento infantil de medo contra o qual tentei lutar, mas neste instante ele chegou ao meu lado, dizendo, "doutor, doutor". Sem parar, eu perguntei, "agora o quê?". Mantendo-se ao meu lado, ele disse, "doutor, o senhor tem que me ajudar, não tenho ninguém no mundo". Respondi com toda autoridade que pude colocar na voz, "arranje um emprego". Ele disse, "eu não sei fazer nada, o senhor tem de me ajudar". Corríamos pela rua. Eu tinha a impressão de que as pessoas nos observavam com estranheza. "Não tenho que ajudá-lo coisa alguma", respondi. "Tem sim, senão o senhor não sabe o que pode acontecer", e ele me segurou pelo braço e me olhou, e pela primeira vez vi bem como era o seu rosto, cínico e vingativo. Meu coração batia, de nervoso e de cansaço. "É a última vez", eu disse, parando e dando dinheiro para ele, não sei quanto. (FONSECA, 1975, p. 71).

Não foi, porém, a última vez. O estado de saúde do executivo se agravou e o motivo, além do excesso de trabalho, parecia ser depositado na inconveniente e diária presença do pedinte. "Todos os dias ele surgia, repentinamente, súplice e ameaçador, caminhando ao meu lado, arruinando a minha saúde [...]. Minha pressão subiu ainda mais, meu coração explodia só de pensar nele. Eu não queria mais ver aquele sujeito, que culpa eu tinha de ele ser pobre?" (FONSECA, 1975, p. 71). A situação desconfortante resultou no afastamento do profissional durante alguns dias do seu escritório com o intuito de restabelecer a sua saúde.

Alguns dias em casa, sem trabalhar e sem encontrar o pedinte, o executivo sentia-se melhor. Contudo, um certo dia decidiu caminhar e chocou-se com o menino. Ao solicitar dinheiro, "ele encostou o seu corpo bem junto ao meu, enquanto caminhávamos, e eu podia sentir o seu hálito azedo e podre de faminto. Ele era mais alto do que eu, forte e ameaçador" (FONSECA, 1975, p. 71-72). A identificação demonstra, pois, receio, medo, insegurança, ao mesmo tempo que caracteriza a situação economicamente hipossuficiente e a ideia de ameaça ou - por que não dizer - do estereótipo de criminoso.

O ápice da relação antagônica, desconfortante e conflituosa entre o executivo e o pedinte, todavia, ainda estava para acontecer. O executivo, na companhia do pedinte, dirigiu-se até a sua casa, onde determinou: "espere aqui" (FONSECA, 1975, p. 72). Em seguida, na narrativa do executivo:

Fechei a porta, fui ao meu quarto. Voltei, abri a porta e ele ao me ver disse "não faça isso, doutor, só tenho o senhor no mundo". Não acabou de falar, ou se falou eu não ouvi, com o barulho do tiro. Ele caiu no chão, então vi que era um menino franzino, de espinhas no rosto, e de uma palidez tão grande que nem mesmo o sangue, que foi cobrindo a sua face, conseguia esconder. (FONSECA, 1975, p. 72).

A história fictícia retratada no conto "O outro" oportuniza a discussão em torno das relações sociais - geralmente, conflituosas - estabelecidas na atualidade entre aqueles que integram o grupo do "eu" e aqueles que compõem o grupo do "outro". A diferença da esfera socioeconômica mostra-se como um fator elementar à conformação da sociedade, uma vez que 
há, de um lado, os bem-afortunados e, de outro lado, os marginalizados. O texto literário de Fonseca (1975) apresenta, simples e realisticamente, o desconforto que o "outro" - pobre provoca na vida dos financeiramente privilegiados.

A literatura, embora seja emanada a partir de histórias ficcionais, é a externalização teórica da realidade. Sem a necessidade de especificar o espaço geográfico e o lapso temporal, o campo das letras oportuniza aos leitores a identificação dos fatos reais cunhados no âmbito da ficção. O mundo real e o mundo ficcional, na compreensão de Antoine Compagnon (2012, p. 133), mantêm-se compatíveis, posto que "[a] literatura mistura continuamente o mundo real e o mundo possível: ela se interessa pelos personagens e pelos acontecimentos reais [...] e a personagem de ficção é um indivíduo que poderia ter existido num outro estado de coisas".

A contribuição literária de Fonseca (1975) é, assim, positiva ao apresentar uma sociedade que tem dificuldade de conviver com o diferente, principalmente quando o "outro" se faz presente, se faz incômodo, se faz constante. No caso ficcional em tela, a solução do executivo, como membro da classe economicamente favorecida, para se afastar do pedinte, como integrante da camada paupérrima da sociedade, foi o homicídio. $\mathrm{O}$ assassinato, sob a justificativa, talvez, de ameaça, medo, insegurança, foi a resposta dada à incapacidade de se conviver com o "outro" e de enxergar no "outro" o seu próprio "eu" como ser humano.

As descrições acerca das características do "outro" variam no decorrer dos encontros com o executivo, em que pese a identificação mais precisa - e humana - seja talvez realizada apenas com a morte. Com exceção da última definição, as demais detalhavam o pedinte com signos de ameaça e perigo (forte; rosto cínico e vingativo; súplice e ameaçador; mais alto do que eu), ao passo que a identificação final, no instante da vida ceifada e, consequentemente, da imposição do "eu" frente ao "outro", se constituiu em descrevê-lo na sua docilidade como um garoto franzino, com espinhas, e pálido.

O debate sobre a criminalidade na sociedade hodierna insere-se na mesma dicotomia do "eu" e do "outro", haja vista que todos aqueles que são inscritos na categoria de "estranho", "inimigo" e "criminoso" são concebidos como - potenciais - ameaças à ordem social. A resposta, tanto social quanto institucional, dada aos sujeitos vestidos sob as marcas da semelhança - logo, do "eu" - é diversa daquela oferecida aos componentes da parcela populacional estereotipada pela ameaça, pelo perigo, pela violência. De tal modo, além da diferente reação dos cidadãos, o Estado age de forma desigual com os pobres.

Há, com efeito, a institucionalização de um aparato jurídico-criminal variável ao indivíduo enquadrado. Segundo David Garland (1999), tem-se, de um lado, a conformação de uma "Criminologia do Eu" e, do lado oposto, a configuração de uma "Criminologia do Outro". 
Trata-se, respectivamente, de ver o criminoso à imagem e semelhança dos demais membros do tecido societal, com o que se banaliza o crime, se moderam os medos e se realiza a prevenção; ou de vê-lo como um ser ameaçador, inquietante, excluído e rancoroso, com o que se demoniza e se postula a máxima punição ao delinquente.

Aqueles que se amoldam aos parâmetros ditados pela sociedade, embora cometam delitos, são inseridos na "Criminologia do Eu", a qual compreende, na reflexão de Fernando Salla, Maitê Gauto e Marcos César Alvarez (2006, p. 346), que "os delinquentes calculam suas ações e o crime é um aspecto trivial da sociedade moderna, um 'risco' que deve ser calculado ou um 'acidente' a ser evitado". Já o "estranho", "inimigo" e "criminoso" é adstrito à “Criminologia do Outro", na qual "o criminoso é uma espécie de monstro, totalmente diferente do indivíduo não-criminoso" (SALLA; GAUTO; ALVAREZ, 2006, p. 346-347).

O estabelecimento de uma leitura criminológica diversa sobre os indivíduos ao cabo de desencadear, para alguns em detrimento de outros, respostas mais amenas significa, de fato, o interesse em retirar certos sujeitos do convívio em coletividade, essencialmente se eles insistirem em manter-se presentes. O conto de Fonseca (1975) é claro ao demonstrar que o desconforto causado pela constante aproximação do pedinte junto ao executivo não se originava do ato de solicitar dinheiro, inclusive porque em momento algum houve menção a isso, mas, sim, à áurea de ameaça, de medo, de perigo que do pobre se supunha exalar.

A relação dicotômica estabelecida socialmente entre o "eu" e o "outro" - que no conto em análise se externa a partir do fator socioeconômico - evidencia a incapacidade de - ou melhor, o desejo de não - entender a diferença do "outro" como elemento que vincula todo o tecido societal: é o caso da desigualdade social. A expressão: "que culpa eu tinha de ele ser pobre?" (FONSECA, 1975, p. 71) é, por si, explicativa, uma vez que afasta a responsabilidade do "eu" para com o "outro", além de culpabilizar exclusivamente o "outro" pela sua condição de hipossuficiência econômica.

O texto literário e a "Criminologia do Outro" demonstram, portanto, a constituição, social e institucional, de visões e atenções diversas, em um mesmo espaço geográfico e lapso temporal, dadas aos indivíduos a depender da situação econômica a que estejam submetidos. A pobreza, nesse contexto, apresenta-se como elemento diferenciador e, inclusive, fortemente incriminador pela violência a ser combatida, não obstante, em regra, a potencialidade delitiva permaneça tão somente na suposição de medo, insegurança e perigo. É a vida e a condição humana do "outro", por fim, que se reflete a seguir sob o prisma da biopolítica. 
WERMUTH, Maiquel Angelo Dezordi; CASTRO, André Giovane de. A criminalização biopolítica da pobreza a partir do conto "O Outro", de Rubem Fonseca

\section{0 pobre despido de ser humano e vestido de homo sacer}

A condição socioeconômica tem o condão de provocar a separação da sociedade em classes antagônicas. A diferença constituída pela desigualdade social desencadeia a conformação de cidadãos em categorias retratadas por aqueles considerados como os "bons" e aqueles estigmatizados como os "maus". A dicotomia do "eu" e do "outro" é a externalização de uma conjuntura atual que se crê vitimar unicamente os integrantes do "eu" - logo, os abastados financeiramente - e culpabilizar os membros do "outro" - via de consequência, os pobres - pela criminalidade e pela violência difusas no tecido societal.

A biopolítica - termo e marco teórico cunhado por Michel Foucault (1999) - alcança, no contexto contemporâneo, um espaço por excelência de sua consolidação. Isso porque a vida biológica ganha importância significativa tanto nos contextos institucionais quanto sociais, uma vez que a adoção de políticas, projetos e programas do Estado se desenvolve com escopo na relevância que se dá à vida dos cidadãos, ao mesmo tempo em que as relações travadas no seio social também se organizam com atenção à expressividade que a vida do próximo tem para $\operatorname{mim}$.

A vida é o aspecto nevrálgico da estruturação estatal e social na atualidade. Por isso, a configuração do poder - seja emanado por quem detém legítima e legalmente uma prerrogativa institucional, seja externado por quem socioeconomicamente se outorga a superioridade perante os outros - representa a elevação da vida ao status de mecanismo e instrumento das relações coletivas. Nesse sentido, a teoria foucaultiana (2005) assenta-se na convicção de que a biopolítica consiste na estatização do biológico em escala global e na assunção da vida como problema político e biológico de regulação e controle populacional.

O problema reside no fato de que, embora a biopolítica tenha o intuito de beneficiar, valorizar e incrementar a vida dos indivíduos, a atuação estatal ou social privilegia a vida de

alguns em detrimento da de outros. É nesse liame em que a disparidade socioeconômica se mostra presente, pois há a seletividade das vidas que importam em prejuízo das vidas que são passivamente elimináveis, no que a categorização de sujeitos como "estranhos", "inimigos" e "criminosos", vindos das classes subalternizadas, se caracteriza como elementar à exclusão e, paradoxalmente, à sua própria inclusão - do corpo social.

As classes concebidas como perigosas, segundo Bauman (2009), sofreram alteração na sua constituição, haja vista que, originalmente, representavam as pessoas temporariamente excluídas e, logo, provisoriamente não reintegráveis à ordem social devido à sua inutilidade funcional ao sistema econômico. Hodiernamente, contudo, os sujeitos caracterizados como 
WERMUTH, Maiquel Angelo Dezordi; CASTRO, André Giovane de. A criminalização biopolítica da pobreza a partir do conto "O Outro", de Rubem Fonseca

perigosos - ou seja, "estranhos", “inimigos" e "criminosos" - são estereotipados como incapacitados à reintegração e "não assimiláveis", isto é, tratam-se de pessoas "supérfluas e excluídas de modo permanente" (BAUMAN, 2009, p. 22, grifos do autor).

A exclusão social significa, atualmente, um "decreto" duradouro estabelecido sobre as vidas que merecem proteção em detrimento daquelas que são deixadas à margem. Diante disso, a configuração do pobre como "estranho", "inimigo" e, consequentemente, "criminoso" referese à conformação das vidas definitivamente apartadas da ordem social. Com efeito, na lição de Bauman (2009, p. 23), constata-se “a irrevogabilidade desse 'despejo' e as escassas possibilidades de recorrer contra essa sentença" como razões transformadoras dos "excluídos de hoje em 'classes perigosas"”.

A partir disto, no instante em que se exclui, de modo definitivo, alguns cidadãos da garantia de pertencimento à mesma comunidade dos demais seres humanos, impõe-se analisar o status de humano que carrega o excluído. Se for considerado que todos são seres humanos e, via de consequência, membros da mesma espécie animal, a mera divisão da sociedade em classes ou categorias - por exemplo, socioeconômica - já demonstra a mitigação da condição humana sobre certos indivíduos e, por derradeiro, a valorização de algumas vidas em prejuízo de outras.

Se o fator socioeconômico, por si, representa, pois, a relativização da vida humana, a identificação do "outro" - notadamente, pobre - como "estranho", "inimigo" e "criminoso" é, por nítido, ainda mais degradante da condição humana. Nesse sentido, consoante Eugenio Raúl Zaffaroni (2007, p. 18, grifos do autor), “"[a] essência do tratamento diferenciado que se atribui ao inimigo consiste em que o direito lhe nega sua condição de pessoa", razão pela qual "só é considerado sob o aspecto de ente perigoso ou daninho". O caráter humano deixa, então, de ser natural para ser fruto de uma teia de relações contextuais.

A corporificação da violência em um conjunto de indivíduos expressa a necessidade de se combater um grupo socialmente definido pelo simples fato de se supor nele a razão do caos. Em uma conjuntura tal, de acordo com Zaffaroni (2007, p. 18, grifos do autor), na qual o ser humano é visto unicamente como perigoso e passível de contenção, “dele é retirado ou negado o seu caráter de pessoa", pois, apesar de alguns direitos continuarem garantidos, a anulação da condição de pessoa não está adstrita ao número de direitos obstados, mas, sim, no motivo pelo qual "alguém é privado de algum direito apenas porque é considerado pura e simplesmente como um ente perigoso".

O que se percebe, nesse contexto, é a transformação do ser humano em ser perigoso ou, em outras palavras, "estranho", "inimigo" e "criminoso". A pobreza despe o sujeito de sua 
WERMUTH, Maiquel Angelo Dezordi; CASTRO, André Giovane de. A criminalização biopolítica da pobreza a partir do conto "O Outro", de Rubem Fonseca

condição humana, razão pela qual integrar as classes economicamente subalternizadas e, por conseguinte, ser estigmatizado como o "outro" são aspectos fundamentais para a seleção das vidas passíveis de, fácil e impunemente, serem eliminadas do tecido societal. Sobre tais vidas, corporifica-se a figura do direito romano arcaico categorizada, conforme Giorgio Agamben (2007), como homo sacer.

O homo sacer é a figura utilizada pela filosofia agambeniana (2007) para retratar, na era contemporânea, a vida nua, ou seja, a vida despida de seu estatuto jurídico-político e constituída tão somente nos seus contornos biológicos, o que, aliás, é próprio de uma sociedade marcadamente biopolítica. A vida nua - irrelevante, insignificante, inútil - diz respeito àqueles indivíduos que se encontram desprotegidos institucional e socialmente, isto é, desabrigados pelo manto do direito - logo, dos direitos humanos - e à mercê da exclusão, seja direta, seja indireta.

Insta salientar, por oportuno, que a redução do caráter humano para a simples condição de "estranho", "inimigo" e "criminoso" dos componentes das selecionadas "classes perigosas" enseja, em que pese não solenemente, a retirada do seu status de sujeito de direitos. Isso se deve à situação de que, se a identificação de alguém como inimigo, à luz de Zaffaroni (2007), ocasiona a negação do seu estado de pessoa, logo, não lhe são assegurados os direitos humanos, justamente porque o requisito único e primordial do sujeito de direitos humanos é o fato de ser humano.

Uma realidade assim constituída delineia o que Agamben (2004) identifica como o estado de exceção. Trata-se de uma decisão do soberano que suspende, total ou parcialmente, o ordenamento jurídico e, por conseguinte, edifica um novo aparato com forma de $\mathrm{ei}^{10}{ }^{10}$, cujo contexto não permite diferenciar o que se encontra dentro e fora do direito, haja vista que o próprio direito é aplicado mediante a sua desaplicação (AGAMBEN, 2004). Em outros termos, a lei do estado de exceção se aplica somente em virtude da suspensão da lei anterior, que, então, é desaplicada, o que, no entanto, não significa o descumprimento da lei.

No Estado Democrático de Direito, a exemplo do Brasil, não há necessariamente um decreto formal emanado soberanamente por quem detém o poder político que instaura o estado de exceção, mas, sim, uma série de circunstâncias que excluem certos indivíduos da proteção dos direitos. A situação vivenciada por aqueles que se encontram à margem da sociedade em razão da pobreza é a retratação desse processo excludente, justamente porque, consoante Castor

\footnotetext{
${ }^{10}$ A grafia é assim em razão de a lei ter somente forma, sem ser, efetivamente, lei.
} 
Mari Martín Bartolomé Ruiz (2012, p. 23), os “[...] excluídos sociais vivem uma exceção de fato porque estão privados de direitos fundamentais para a vida humana [...]”.

Os integrantes das classes economicamente hipossuficientes são, a partir disso, não destituídos formalmente de seu status de sujeito de direitos, mas, sim, marginalizados e abandonados ${ }^{11}$. Nesse sentido, a almejada vida digna do pobre é obstada devido à privação de direitos considerados básicos e solenemente proclamados tanto no âmbito nacional quanto internacional. Por derradeiro, conforme Ruiz (2012, p. 24), nele "se abate um estado de exceção de fato que lhe retira direitos básicos da existência humana condenando sua vida a uma sobrevivência indigna que, em muitos casos, conduz diretamente para a morte [...]".

A seletividade penal sustenta-se na cisão entre os sujeitos de direitos e os sujeitos que, embora formalmente continuem como titulares, foram excluídos de sua salvaguarda. Emergese, com efeito, na visão de Mendes e Simioni (2020, p. 65), "o apagamento de determinados indivíduos", os quais são incluídos em "um sistema permanentemente seletivo e que rejeita e elimina o diferente", qual seja: o homo sacer. A biopolítica mostra, assim, o seu fervor, com ênfase ao controle social, "criando um expurgo humano de seres não produtivos aos olhos do soberano" (MENDES; SIMIONI, 2020, p. 69).

A criminalização dos segmentos menos abastados do tecido societal encontra-se, nesse sentido, relacionada ao poder dos corpos político-social. Tal fenômeno de cesura evidencia e favorece, de acordo com Mendes e Simioni (2020, p. 69), "a manutenção e legitimação dos interesses dominantes" através da gestão da vida. A biopolítica viabiliza, consequentemente, a separação entre as vidas dignas e as vidas indignas, as quais, de um lado, são abrangidas pelo manto protetivo do Estado e, de outro lado, são reduzidas da sua condição humana e mantidas sob a condição de homines sacri.

A morte é inerente à figura do homo sacer, pois, na análise agambeniana (2007), consiste naquele que, na Antiguidade, se encontrava em um espaço de indistinção do direito humano e do direito divino, haja vista que, ao mesmo tempo em que o seu homicídio não desencadearia sanção ao agressor, o seu corpo não poderia ser entregue a sacrifício aos deuses dada, pois, a irrelevância de sua vida. O homo sacer representa, então, de acordo com Diel e Wermuth (2018, p. 32), "a vida que não vale a pena ser vivida e que deve ser excluída do meio social, ensejando uma morte simbólica" ou mesmo concreta.

\footnotetext{
${ }^{11}$ Aliás, o abandono é próprio do estado de exceção, uma vez que se refere ao que a teoria agambeniana (2007) denomina de bando, o qual se constitui pelas vidas excluídas do direito e incluídas na relação de bando por determinação soberana. Para Agamben (2007, p. 117), “[o] bando é propriamente a força, simultaneamente atrativa e repulsiva, que liga os dois polos da exceção soberana: a vida nua e o poder, o homo sacer e o soberano".
} 
A vida daqueles concebidos como "estranhos", "inimigos" e "criminosos" é despida do seu estado de bíos, uma vez que perde a sua qualificação de pessoa e de sujeito de direitos, e vestida do caráter de zoé, haja vista que vive tão somente no seu sentido natural, biológico e existencial. Hoje, porém, principalmente em um Estado Democrático de Direito, não é possível dizer, consoante Diel e Wermuth (2018, p. 93), que o homo sacer esteja plenamente destituído da sua condição cívica e humana, "mas sobrevive sob a constante ameaça da suspensão de direitos fundamentais".

A marginalidade socioeconômica apresenta-se, portanto, como fator de configuração das classes perigosas e, consequentemente, do "estranho", inimigo" e "criminoso" a ser excluído, direta ou indiretamente, do tecido societal. A biopolítica, à vista do exposto, constituise como a matriz por excelência do poder institucional e social contemporâneo capaz de promover a seletividade dos homines sacri, a conformação de vidas nuas e, por fim, a passível eliminação de certos "humanos" dada a irrelevância, insignificância e inutilidade de suas vidas, como é o caso dos pobres.

\section{Conclusão}

O artigo assumiu a proposta de investigar as imbricações da desigualdade social e da violência no âmago de um contexto marcadamente biopolítico da contemporaneidade. O estudo problematizou a pobreza como elemento categorizador dos indivíduos em situação de marginalidade socioeconômica como "estranhos", "inimigos", "criminosos" e, logo, como culpabilizados pela criminalidade a ser combatida social e institucionalmente. A atuação do Estado no tocante aos sujeitos economicamente hipossuficientes, a relação entre membros de classes antagônicas e os direitos humanos foram os pilares da discussão.

A pobreza apresenta-se, atualmente, como elemento característico dos medos, das ameaças e dos perigos vivenciados na sociedade. Os integrantes das classes paupérrimas, além das mazelas da condição socioeconômica e da ineficiência estatal frente à sua função de bemestar, são configurados como "estranhos", "inimigos" e "criminosos". A culpabilização a respeito da criminalidade parece ser corporificada nos pobres, os quais são socialmente estigmatizados, independentemente da externalização de condutas delitivas, e, com efeito, responsabilizados potencialmente pela violência combatida.

O conto "O outro", de Rubem Fonseca, constitui-se como a retratação literária de uma conjuntura de enfrentamento entre classes economicamente diversas. Os personagens, que evidenciam o embate entre privilegiados e desprivilegiados, demonstram a incapacidade de se 
conviver com a diferença e o estereótipo de "estranho", "inimigo" e "criminoso" incutido no pobre. Tal cenário exalta a conformação da sociedade em categorias como "eu" e "outro", com reflexos, inclusive, na esfera repressivo-punitiva, como é o caso da "demonização" do delinquente pela "Criminologia do Outro".

A configuração social e institucional do "estranho", "inimigo" e "criminoso" consiste, com escopo na matriz teórica da biopolítica, na conformação das vidas indignas, irrelevantes, insignificantes, inúteis e, via de consequência, passivamente elimináveis do tecido societal. O pobre inscreve-se na figura do homo sacer, pois, além de se localizar economicamente à margem, se encontra responsabilizado pela marginalidade. $\mathrm{O}$ abandono dos membros das classes subalternizadas transforma-os em vida nua e, por derradeiro, relativiza a condição humana.

A desigualdade social, portanto, ao corroborar a hipótese emergente da discussão, está intimamente vinculada à violência. Não porque os pobres sejam necessariamente os promotores da criminalidade, mas, sim, porque neles se incute a potencialidade delitiva a partir da categorização como "estranhos, "inimigos" e "criminosos". A vulnerabilidade socioeconômica deixa, por fim, de ser um aspecto de atenção da sociedade e do Estado no seu sentido assistencial, caritativo, providencial para atender ao viés excludente de um corpo social notadamente biopolítico e centrado, contemporaneamente, em um Estado penal.

\section{Referências}

AGAMBEN, Giorgio. Estado de exceção. Tradução de Iraci D. Poleti. São Paulo: Boitempo Editorial, 2004.

AGAMBEN, Giorgio. Homo sacer: o poder soberano e a vida nua I. Tradução de Henrique Burigo. Belo Horizonte: UFMG, 2007.

ARENDT, Hannah. Da violência. Tradução de Maria Claudia Drummond Trindade. Brasília: Universidade de Brasília, 1985.

BAUMAN, Zygmunt. Confiança e medo na cidade. Tradução de Eliana Aguiar. Rio de Janeiro: Zahar, 2009.

BAUMAN, Zygmunt. Globalização: as consequências humanas. Tradução de Marcus Penchel. Rio de Janeiro: Zahar, 1999.

BAUMAN, Zygmunt. Modernidade líquida. Tradução de Plínio Dentzien. Rio de Janeiro: Zahar, 2014.

BAUMAN, Zygmunt. O mal-estar da pós-modernidade. Tradução de Mauro Gama e Cláudia Martinelli Gama. Rio de Janeiro: Zahar, 1998. 
BAUMAN, Zygmunt. Tempos líquidos. Tradução de Carlos Alberto Medeiros. Rio de Janeiro: Zahar, 2007.

BECK, Ulrich. Sociedade de risco: rumo a uma outra modernidade. Tradução de Sebastião Nascimento. São Paulo: Editora 34, 2010.

BRASIL. Constituição da República Federativa do Brasil de 1988. Disponível em: http://www.planalto.gov.br/ccivil_03/constituicao/constituicaocompilado.htm. Acesso em: 24 nov. 2018.

BRASIL. Levantamento Nacional de Informações Penitenciárias: Atualização - Junho de 2017. Organização de Marcos Vinícius Moura Silva. Brasília: Ministério da Justiça e Segurança Pública; Departamento Penitenciário Nacional, 2019. Disponível em: http://depen.gov.br/DEPEN/depen/sisdepen/infopen/relatorios-sinteticos/infopen-jun-2017rev-12072019-0721.pdf. Acesso em: 24 maio 2020.

BRASIL. Levantamento Nacional de Informações Penitenciárias: Infopen Mulheres. 2. ed. Organização de Thandara Santos. Brasília: Ministério da Justiça e Segurança Pública; Departamento Penitenciário Nacional, 2018. Disponível em: http://depen.gov.br/DEPEN/depen/sisdepen/infopen-mulheres/infopenmulheres_arte_07-0318.pdf. Acesso em: 24 maio 2020.

COMPAGNON, Antoine. O demônio da teoria: literatura e senso comum. Tradução de Cleonice Paes Barreto Mourão e Consuelo Fortes Santiago. 2. ed. Belo Horizonte: UFMG, 2012.

DIAS, Camila Caldeira Nunes. Encarceramento, seletividade e opressão: a "crise carcerária" como projeto político. São Paulo: Friedrich Ebert Stiftung. Análise no 28/2017. Disponível em: http://library.fes.de/pdf-files/bueros/brasilien/13444.pdf. Acesso em: 24 maio 2020.

DIEL, Aline Ferreira da Silva; WERMUTH, Maiquel Ângelo Dezordi. Mídia, direito penal e o estereótipo do criminoso: uma leitura biopolítica. Curitiba: CRV, 2018.

DORNELLES, João Ricardo. Conflito e segurança: entre pombos e falcões. 2. ed. Rio de Janeiro: Lumen Juris, 2008.

FONSECA, Rubem. Feliz ano novo. Rio de Janeiro: Artenova, 1975.

FOUCAULT, Michel. Em defesa da sociedade: curso no Collège de France (1975-1976). Tradução de Maria Ermantina Galvão. São Paulo: Martins Fontes, 2005.

FOUCAULT, Michel. História da sexualidade I: a vontade de saber. Tradução de Maria Thereza da Costa Albuquerque e J. A. Guilhon Albuquerque. 13. ed. Rio de Janeiro: Edições Graal, 1999.

GADAMER, Hans-Georg. Verdade e método: traços fundamentais de uma hermenêutica filosófica. Tradução de Flávio Paulo Meurer. 3. ed. Petrópolis: Vozes, 1999. 
GARLAND, David. As contradições da "sociedade punitiva": o caso britânico. Revista de Sociologia e Política, Curitiba, n. 13, p. 59-80, 1999. Disponível em:

https://revistas.ufpr.br/rsp/article/view/39244/24065. Acesso em: 24 nov. 2018.

HEIDEGGER, Martin. Ser e tempo: parte 1. Tradução de Márcia de Sá Cavalcante. 7. ed. Petrópolis: Vozes, 1998.

MENDES, Érick de Freitas; SIMIONI, Rafael Lazzarotto. O paradigma político de gestão da vida nua e o homo sacer no núcleo da seletividade penal. Profanações, [S.l.], v. 7, p. 56-71, 2020. Disponível em: http://www.periodicos.unc.br/index.php/prof/article/view/2352. Acesso em: 24 maio 2020.

PASTANA, Débora Regina. Estado punitivo brasileiro: a indeterminação entre democracia e autoritarismo. Civitas - Revista de Ciências Sociais, Porto Alegre, v. 13, n. 1, p. 27-47, jan./abr. 2013. Disponível em:

http://revistaseletronicas.pucrs.br/ojs/index.php/civitas/article/view/9039. Acesso em: 24 maio 2020.

PESSOA, Sara de Araújo; LIMA, Fernanda da Silva. Racismo e política criminal: uma análise a partir do Documentário $13^{\text {th }}-13^{\text {a }}$ Emenda. Revista Thesis Juris - RTJ, São Paulo, v. 8, n. 2, p. 275-294, jul./dez. 2019. Disponível em:

https://periodicos.uninove.br/index.php?journal=thesisjuris\&page $=$ article \&op $=$ view $\& p a t h \% 5$ $\mathrm{B} \% 5 \mathrm{D}=10763 \&$ path\%5B\%5D=pdf. Acesso em: 24 maio 2020.

RUIZ, Castor Mari Martín Bartolomé. A sacralidade da vida na exceção soberana, a testemunha e sua linguagem: (re) leituras biopolíticas da obra de Giorgio Agamben. Cadernos IHU, ano 10, n. 39. São Leopoldo: Instituto Humanitas Unisinos, 2012.

SALLA, Fernando; GAUTO, Maitê; ALVAREZ, Marcos César. A contribuição de David Garland: a sociologia da punição. Revista Tempo Social, São Paulo, v. 18, n. 1, p. 329-350, 2006. Disponível em: https://www.revistas.usp.br/ts/article/view/12505. Acesso em: 25 nov. 2018.

SINHORETTO, Jacqueline; LIMA, Renato Sérgio de. Narrativa autoritária e pressões democráticas na segurança pública e no controle do crime. Contemporânea - Revista de Sociologia da UFSCar, São Carlos, v. 5, n. 1, p. 119-141, jan./jun. 2015. Disponível em: http://www.contemporanea.ufscar.br/index.php/contemporanea/article/view/299/131. Acesso em: 24 maio 2020.

STEIN, Ernildo. Compreensão e finitude: estrutura e movimento da interrogação heideggeriana. Ijuí: Unijuí, 2001.

WACQUANT, Loïc. Punir os pobres: a nova gestão da miséria nos Estados Unidos [a onda punitiva]. Tradução de Sérgio Lamarão. 3. ed. rev. e ampl. Rio de Janeiro: Revan, 2007.

WEDY, Miguel Tedesco. A eficiência e sua repercussão no direito penal e no processo penal. Porto Alegre: Elegantia Juris, 2016.

ZAFFARONI, Eugenio Raúl. O inimigo no direito penal. Tradução de Sérgio Lamarão. 2. ed. Rio de Janeiro: Revan, 2007. 